\title{
PERCEPÇÃO DOS PROFISSIONAIS DE ENFERMAGEM QUANTO AO TRABALHO EM EQUIPE
}

\author{
PERCEPTION OF NURSING PROFESSIONALS \\ REGARDING TEAMWORK
}

\section{LA PERCEPCIÓN DE LOS PROFESIONALES DE LA ENFERMERÍA SOBRE EL TRABAJO EN EQUIPO}

\author{
Lusinete Ventura Valentim ${ }^{1}$ \\ Reginaldo Adalberto de $\mathrm{Luz}^{2}$ \\ Luciana Soares Costa Santos ${ }^{3}$ \\ Cell Regina da Silva Noca ${ }^{4}$
}

Como citar este artigo: Valentim LV, Luz RA, Santos LSC, Noca CRS. Percepção dos profissionais de enfermagem quanto ao trabalho em equipe. Rev baiana enferm. 2020;34:e37510.

Objetivo: conhecer a percepção dos profissionais de enfermagem quanto ao trabalho em equipe. Método: estudo transversal, exploratório, realizado em um hospital geral de grande porte, privado, na cidade de São Paulo. Resultados: amostra composta por 63\% de técnicos de enfermagem e 37\% de enfermeiros. Quanto ao trabalho em equipe, 95\% concordaram ter bom relacionamento entre pares, receberem ajuda quando atarefados e retribuí-la; $94,6 \%$ atendiam a campainha, mesmo não sendo sua. Quanto aos benefícios do trabalho em equipe, 99,1\% concordaram que a colaboração entre colegas de trabalho facilitava a assistência; 94,6\%, que diminuía o tempo de resposta às chamadas; 96,4\%, que o resultado do trabalho em equipe era mérito coletivo. Conclusão: os profissionais de enfermagem reconheceram fatores favorecedores do trabalho em equipe, como bom relacionamento interpessoal e clareza nos objetivos da instituição, além dos benefícios propiciados, como o papel do enfermeiro no desenvolvimento e como facilitador dessa dinâmica de trabalho.

Descritores: Equipe de Enfermagem. Relações Interpessoais. Comportamento Cooperativo. Percepção. Trabalho.

Objective: to know the perception of nursing professionals regarding teamwork. Method: transversal, exploratory study, carried out in a large, private, general hospital in the city of São Paulo. Results: sample composed by 63\% of nursing technicians and 37\% of nurses. As for teamwork, 95\% agreed to have good relationships among peers, receive help when busy and give it back; $94.6 \%$ answered the bell, even though it was not theirs. As for the benefits of teamwork, 99.1\% agreed that collaboration among co-workers facilitated assistance; $94.6 \%$ reduced response time to calls; $96.4 \%$ that the result of teamwork was collective merit. Conclusion: the nursing professionals recognized factors favoring teamwork, such as good interpersonal relationship and clarity in the objectives of the institution, in addition to the benefits provided, such as the role of the nurse in the development and as a facilitator of this work dynamic.

Descriptors: Nursing Team. Interpersonal Relations. Cooperative Behavior. Perception. Work.

\footnotetext{
Enfermeira. Especialista em Enfermagem em Centro Cirúrgico, Recuperação Anestésica e Central de Material e Esterilização. Enfermeira do Hospital Samaritano Paulista. São Paulo, SP, Brasil. http://orcid.org/0000-0002-7988-6099.

Enfermeiro. Doutor e Mestre em Ciências. Docente da Faculdade de Ciências Médicas da Santa Casa de São Paulo. São Paulo, SP, Brasil. http://orcid.org/0000-00034622-0925.

3 Enfermeira. Mestre em Ciências. Doutora em Ciências. Docente da Faculdade de Ciências Médicas da Santa Casa de São Paulo. São Paulo, SP, Brasil. luciana.santos@fcmsantacasasp.edu.br. http://orcid.org/0000-000I-5708-I460.

4 Enfermeira. Licenciatura em Educação. Mestre em Saúde Pública. Doutora em Saúde Pública. Docente da Faculdade de Ciências Médicas da Santa Casa de São Paulo. São Paulo, SP, Brasil. http://orcid.org/0000-0003-3 I08-385X.
} 
Objetivo: conocer la percepción de los profesionales de la enfermería sobre el trabajo en equipo. Método: estudio transversal y exploratorio, realizado en un gran hospital general privado de la ciudad de São Paulo. Resultados: muestra compuesta por el 63\% de técnicos de enfermería y el $37 \%$ de enfermeras. En cuanto al trabajo en equipo, el 95\% aceptó tener buenas relaciones entre pares, recibir ayuda cuando estaba ocupado y devolverla; el 94,6\% respondió al timbre, aunque no era suyo. En cuanto a los beneficios del trabajo en equipo, el 99, 1\% estuvo de acuerdo en que la colaboración entre los compañeros de trabajo facilitaba la asistencia; el 94,6\% redujo el tiempo de respuesta a las llamadas; el 96,4\% consideró que el resultado del trabajo en equipo era un mérito colectivo. Conclusión: los profesionales de la enfermería reconocieron factores que favorecen el trabajo en equipo, como la buena relación interpersonal y la claridad en los objetivos de la institución, además de los beneficios proporcionados, como el papel de la enfermera en el desarrollo y como facilitadora de esta dinámica de trabajo.

Descritores: Equipo de Enfermería. Relaciones Interpersonales. Comportamiento Cooperativo. Percepción. Trabajo.

\section{Introdução}

Define-se equipe quando ocorre a união de pessoas com personalidades diferentes, mas com responsabilidades e objetivos em comum, que, mesmo em momentos difíceis, procuram resolver as situações e os conflitos com maturidade e inteligência, sem a pretensão de obter mérito individual $^{(1)}$. O trabalho em equipe, na área da saúde, interprofissional, teve início na década de 1960, com o objetivo de promover a interação entre os profissionais, atender o paciente integralmente, com toda a sua complexidade, e favorecer a formação dos profissionais da saúde na prática ${ }^{(2)}$. O sucesso do trabalho em equipe é dependente de fatores, tais como confiança, boa comunicação, aceitação das diferenças, valorização de habilidades individuais, conhecimento dos objetivos esperados e cooperação mútua ${ }^{(1,3-5)}$.

A enfermagem é uma profissão essencialmente voltada ao trabalho em equipe, sendo impossível prestar um atendimento integral ao cliente sem a colaboração de todos. Trata-se de uma profissão que exige continuidade dos cuidados e interdependência das funções, isto é, cada profissional que realiza uma função, necessita do outro para promover uma assistência completa. Esse conjunto de ações compõe a equipe de enfermagem, que é composta por enfermeiros, auxiliares e técnicos de enfermagem. Entretanto, o enfermeiro é o profissional responsável por gerenciar e supervisionar as atividades, exercendo seu papel de líder ${ }^{(2,3,5)}$.

A maneira pela qual o líder coordena seus liderados pode influenciar no resultado esperado.
O líder deve saber ouvir, ser imparcial em suas decisões, ter maturidade ao enfrentar as dificuldades, manter uma comunicação clara, respeitar a diversidade de conhecimentos dos integrantes da equipe e utilizá-la como estratégia para obter uma equipe completa ${ }^{(3-5)}$.

Algumas barreiras podem dificultar o trabalho em equipe, tais como: falta de reconhecimento do trabalho pelos colegas ${ }^{(6)}$; falta de colaboração dos colegas, o que gera insatisfação e distanciamento dos integrantes da equipe ${ }^{(7)}$; conflitos gerados no dia a dia ${ }^{(5)}$; falta de clareza dos objetivos; e divergência entre os objetivos pessoais e os da equipe ${ }^{(8)}$.

Este estudo tem como objetivo conhecer a percepção dos profissionais de enfermagem quanto ao trabalho em equipe.

\section{Método}

Trata-se de um estudo transversal, exploratório e de campo, realizado em um hospital geral de grande porte, privado, localizado na cidade de São Paulo, Brasil. Os sujeitos da pesquisa foram os enfermeiros e técnicos de enfermagem que trabalhavam nas unidades de Clínica Médica e aceitaram participar do estudo.

Os dados foram coletados por meio de um questionário contendo 16 perguntas relacionadas ao trabalho em equipe na enfermagem, com opções de resposta na forma de uma escala do tipo Likert. O pesquisador entregou pessoalmente o questionário ao participante juntamente com o Termo de Consentimento Livre e Esclarecido 
(TCLE), explicou o objetivo da pesquisa e como ocorreria a participação no estudo, que seria voluntária e de caráter sigiloso. Após a assinatura do TCLE e o preenchimento do questionário, ambos foram recolhidos pelo escriturário de cada setor no prazo máximo de cinco dias.

O escriturário recebeu os impressos, conferiu se o termo estava assinado e o questionário preenchido, embaralhou-os para manter a confidencialidade, guardou em uma pasta com lacre, para devolver oportunamente ao pesquisador. Após o recolhimento, os dados foram digitados e armazenados em uma planilha do Microsoft Excel®.

O estudo foi aprovado pelo Comitê de Ética em Pesquisa (CEP) da Irmandade da Santa Casa de Misericórdia de São Paulo, conforme Certificado de Apresentação de Apreciação Ética (CAAE) $\mathrm{n}^{\circ}$ 46282415.2.0000.5479, bem como pelo CEP da instituição coparticipante, pelo CAAE n ${ }^{\circ} 46282415.2 .3001 .0062$.

\section{Resultados}

Participaram da pesquisa 111 profissionais de enfermagem. Os técnicos de enfermagem totalizaram 70 (63\%) e os enfermeiros 41 (37\%). A idade dos enfermeiros participantes variou de 23 a 51 anos, com uma média de 33,9 anos (DP 6,9 anos) enquanto a idade média dos técnicos de enfermagem foi de 36,1 anos (variação de 21 a 55 anos; DP 7,6). Quanto ao sexo, 36 (88\%) participantes da amostra composta por enfermeiros foram mulheres e 5 (12\%) homens.
O tempo de formação profissional dos enfermeiros foi, em média, de 8,2 anos (variação de 0,8 a 30 anos; DP 5,6) e o tempo em que trabalhavam na instituição correspondeu à média de 4,7 anos (variação de 0,3 a 21 anos; DP 5,1). Quanto aos técnicos de enfermagem, a média de tempo em que haviam concluído sua formação técnica foi de 11,6 anos, com uma variação de 2 a 26 anos (DP 6). Estes profissionais informaram que trabalhavam na instituição há 6,6 anos em média (variação de 0,3 a 30 anos; DP 6,8).

Observou-se que 77 (70\%) participantes eram do setor de clínica médica, seguido por 33 (30\%) da clínica cirúrgica. Com relação ao turno de trabalho, 38 (35\%) trabalhavam no período matutino, seguido por 32 (29\%) do período vespertino. Os demais profissionais trabalhavam no período noturno.

Quanto às perguntas que remetiam ao que poderia facilitar o trabalho em equipe, 95\% dos participantes concordaram que ter um bom relacionamento entre colegas de trabalho, oferecer ajuda ao colega atarefado e retribuir a ajuda recebida, além de conhecer os objetivos da instituição e dos seus superiores. Dentre os participantes, 96 profissionais $(87,3 \%)$ afirmaram sempre pedir ajuda ao colega quando estavam sobrecarregados e 10 (9,1\%) não o faziam; 105 (94,6\%) concordaram que tinham a responsabilidade de atender a campainha do cliente que não estava na sua escala (Tabela 1).

Tabela 1 - Afirmativas do trabalho em equipe, segundo grau de concordância. São Paulo, SP, Brasil $-2015$

(continua)

\begin{tabular}{|c|c|c|c|c|c|c|c|c|c|c|c|}
\hline \multirow[t]{2}{*}{ Afirmativas } & \multicolumn{2}{|c|}{$\begin{array}{l}\text { Concordo } \\
\text { totalmente }\end{array}$} & \multicolumn{2}{|c|}{ Concordo } & \multicolumn{2}{|c|}{ Indiferente } & \multicolumn{2}{|c|}{ Discordo } & \multicolumn{2}{|c|}{$\begin{array}{c}\text { Discordo } \\
\text { totalmente }\end{array}$} & \multirow[t]{2}{*}{ Total } \\
\hline & $\mathbf{n}$ & $(\%)$ & $\mathbf{n}$ & $(\%)$ & $\mathbf{n}$ & $(\%)$ & $\mathbf{n}$ & $(\%)$ & $\mathbf{n}$ & $(\%)$ & \\
\hline $\begin{array}{l}\text { Ter um bom relacionamento } \\
\text { entre colegas de trabalho } \\
\text { facilita o trabalho em equipe. }\end{array}$ & 85 & $(77)$ & 23 & (21) & 2 & (2) & 1 & (1) & - & - & 111 \\
\hline $\begin{array}{l}\text { Quando percebo que o meu } \\
\text { colega está atarefado, ofereço } \\
\text { apoio. }\end{array}$ & 59 & $(54)$ & 48 & $(44)$ & 3 & (3) & - & - & - & - & 110 \\
\hline $\begin{array}{l}\text { Durante o meu expediente } \\
\text { de trabalho, se o meu colega } \\
\text { me oferece ajuda, acho justo } \\
\text { também oferecer a ele. }\end{array}$ & 55 & $(50)$ & 53 & $(48)$ & 2 & (2) & 1 & (1) & - & - & 111 \\
\hline
\end{tabular}


Tabela 1 - Afirmativas do trabalho em equipe, segundo grau de concordância. São Paulo, SP, Brasil $-2015$

\begin{tabular}{|c|c|c|c|c|c|c|c|c|c|c|c|}
\hline \multirow[t]{2}{*}{ Afirmativas } & \multicolumn{2}{|c|}{$\begin{array}{c}\text { Concordo } \\
\text { totalmente }\end{array}$} & \multicolumn{2}{|c|}{ Concordo } & \multicolumn{2}{|c|}{ Indiferente } & \multicolumn{2}{|c|}{ Discordo } & \multicolumn{2}{|c|}{$\begin{array}{c}\text { Discordo } \\
\text { totalmente }\end{array}$} & \multirow[t]{2}{*}{ Total } \\
\hline & $\mathbf{n}$ & (\%) & $\mathbf{n}$ & $(\%)$ & $\mathbf{n}$ & (\%) & $\mathbf{n}$ & (\%) & $\mathbf{n}$ & $(\%)$ & \\
\hline $\begin{array}{l}\text { Conhecer os objetivos } \\
\text { da instituição e dos meus } \\
\text { superiores facilita a minha } \\
\text { participação na equipe da } \\
\text { qual faço parte. }\end{array}$ & 69 & (62) & 38 & (34) & 3 & (3) & 1 & (1) & - & - & 111 \\
\hline $\begin{array}{l}\text { Eu sempre solicito ajuda ao } \\
\text { meu colega quando estou } \\
\text { sobrecarregado. }\end{array}$ & 65 & (59) & 31 & (28) & 4 & (4) & 10 & (9) & - & - & 110 \\
\hline $\begin{array}{l}\text { Eu tenho a responsabilidade } \\
\text { de atender a campainha do } \\
\text { cliente que não está na minha } \\
\text { escala. }\end{array}$ & 63 & (57) & 42 & (38) & 3 & (3) & 2 & (2) & 1 & (1) & 111 \\
\hline $\begin{array}{l}\text { A liderança facilita diretamente } \\
\text { o andamento da equipe. }\end{array}$ & 54 & $(49)$ & 46 & $(41)$ & 7 & (6) & 2 & (2) & 2 & (2) & 111 \\
\hline $\begin{array}{l}\text { O reconhecimento e a } \\
\text { valorização pelo meu trabalho } \\
\text { influenciam na minha } \\
\text { participação no grupo. }\end{array}$ & 48 & (43) & 46 & $(41)$ & 13 & (12) & 4 & (4) & - & - & 111 \\
\hline $\begin{array}{l}\text { A colaboração entre colegas } \\
\text { de trabalho facilita a } \\
\text { assistência ao cliente. }\end{array}$ & 75 & $(68)$ & 35 & $(32)$ & 1 & (1) & 0 & (0) & - & - & 111 \\
\hline $\begin{array}{l}\text { O trabalho em equipe diminui } \\
\text { o tempo de resposta às } \\
\text { chamadas do cliente. }\end{array}$ & 59 & (53) & 46 & $(41)$ & 2 & (2) & 3 & (3) & 1 & (1) & 111 \\
\hline $\begin{array}{l}\text { O trabalho em equipe é } \\
\text { essencial na minha profissão. }\end{array}$ & 61 & (55) & 40 & (36) & 3 & (3) & 6 & (5) & 1 & (1) & 111 \\
\hline $\begin{array}{l}\text { A minha motivação afeta } \\
\text { diretamente o andamento da } \\
\text { equipe. }\end{array}$ & 59 & (53) & 37 & (33) & 6 & (5) & 7 & (6) & 2 & (2) & 111 \\
\hline $\begin{array}{l}\text { No trabalho em equipe, o } \\
\text { resultado final é mérito de } \\
\text { todos os integrantes e não só } \\
\text { meu. }\end{array}$ & 66 & (59) & 41 & (37) & 2 & (2) & 0 & (0) & 2 & (2) & 111 \\
\hline $\begin{array}{l}\text { A maioria dos profissionais de } \\
\text { enfermagem do meu setor de } \\
\text { trabalho consegue fazer bem } \\
\text { um "trabalho em equipe". }\end{array}$ & 59 & (53) & 31 & $(28)$ & 13 & (12) & 8 & (7) & - & - & 111 \\
\hline $\begin{array}{l}\text { No meu setor, o trabalho em } \\
\text { equipe acontece de forma } \\
\text { satisfatória e eficiente. }\end{array}$ & 54 & $(49)$ & 34 & (31) & 18 & (16) & 5 & (5) & - & - & 111 \\
\hline $\begin{array}{l}\text { O enfermeiro é o principal } \\
\text { responsável pelo trabalho em } \\
\text { equipe ser da forma como é } \\
\text { atualmente no meu setor. }\end{array}$ & 55 & $(50)$ & 21 & (19) & 18 & (16) & 12 & (11) & 4 & (4) & 110 \\
\hline
\end{tabular}

Fonte: Elaboração própria.

Nota: Sinal convencional utilizado:

- Dado numérico igual a zero não resultante de arredondamento.

Em relação à influência da liderança no trabalho em equipe e valorização do trabalho, 16\% dos profissionais consideraram que não havia interferência ou até mesmo consideraram indiferente, enquanto $43 \%$ dos colaboradores afirmaram que o reconhecimento e a valorização 
pelo seu trabalho influenciavam na sua participação no grupo.

Quanto aos benefícios que o trabalho em equipe pode trazer para a assistência ao paciente, $110(99,1 \%)$ participantes concordaram que a colaboração entre colegas de trabalho facilitava a assistência ao cliente e 105 (94,6\%) concordaram que o trabalho em equipe diminuía o tempo de resposta às chamadas do cliente. Mesmo assim, 9\% dos profissionais perceberam que não era importante ou era indiferente para a profissão.

Já a motivação, na opinião dos profissionais, afetava diretamente o andamento da equipe, como indicaram $15(13,5 \%)$ profissionais da amostra e 107 (96,4\%) concordaram que, no trabalho em equipe, o resultado era mérito de todos os integrantes.

Com relação à realidade no ambiente de trabalho, 21 (18,9\%) membros da equipe de enfermagem foram indiferentes ou não concordaram que a maioria dos profissionais de enfermagem do seu setor conseguia fazer bem o "trabalho em equipe" e $23(20,7 \%)$ não concordaram ou foram indiferentes quanto à afirmativa de que o trabalho em equipe acontecia de forma satisfatória e eficiente.

Quando perguntados se concordavam que o enfermeiro era o profissional responsável pelo trabalho em equipe, atualmente, no seu setor, 34 (30,9\%) não concordaram ou mostraram-se indiferentes.

\section{Discussão}

O trabalho em equipe tem sido valorizado cada vez mais, não só pela demanda das atividades no âmbito de trabalho, mas principalmente por propiciar a agilidade na execução da tarefa, a qualidade no serviço prestado e a comunicação eficaz entre profissionais e instituição, o que, consequentemente, facilita o alcance das metas institucionais. Essa união é imprescindível em qualquer ramo de atividade e/ou profissão, mas, na enfermagem, é essencial ${ }^{(9-10)}$.

A harmonia, a interação, o profissionalismo e o comprometimento de todos os membros da equipe determinam a eficiência no cuidado prestado. A equipe de enfermagem é liderada pelo enfermeiro, que é capaz de influenciar no direcionamento da sua equipe para o trabalho coletivo, em busca dos melhores resultados ${ }^{(5,10-11)}$.

A interação entre os profissionais de enfermagem pode não resultar em acordos, o que desencadeia inúmeros conflitos. No entanto, esta situação pode ter significados ambíguos, a depender da condução do problema. Dessa forma, destaca-se a importância do papel do enfermeiro em conduzir o trabalho em equipe para minimizar situações de conflito e impactar nos resultados do cuidado ${ }^{(7)}$.

Estudo realizado com profissionais da Estratégia da Saúde da Família (ESF) aponta para a ocorrência do trabalho em equipe com a necessidade da colaboração entre os membros, com troca de conhecimentos e complementariedade das atividades de trabalho, pressupondo relações colaborativas e comunicativas, contribuindo para o desenvolvimento do trabalho sustentado em relação dialogada e horizontal ${ }^{(12)}$. Embora o estudo tenha sido realizado na ESF, pode-se inferir que o princípio do trabalho em equipe torna-se único e essencial para melhores resultados.

No trabalho em equipe desenvolvido pela equipe de Enfermagem, o enfermeiro, pela sua formação, torna-se um líder essencial. Por isso, deve desenvolver seu potencial de liderança, de modo que possa desempenhar o trabalho utilizando ferramentas importantes, como comunicação e processo de melhoria na condução de sua equipe, por meio da gestão participativa ${ }^{(13)}$.

O bom relacionamento entre os membros da equipe de enfermagem é um fator de extrema importância para a assistência com qualidade e segurança ao paciente, pois facilita a comunicação, promove um ambiente de ajuda mútua e de interação multiprofissional ${ }^{(14)}$. Assim, corrobora os achados deste estudo, pesquisa ${ }^{(14)}$ que aponta o reconhecimento do bom relacionamento interpessoal como um fator relevante para o trabalho em equipe, ainda que alguns colaboradores tenham admitido que não solicitavam ajuda dos colegas, quando precisavam. Essa postura demonstra a possibilidade de não haver integração entre os membros da equipe 
e evidencia a individualização nas tarefas, posturas que resultam no distanciamento entre os colaboradores, na sobrecarga de trabalho e na inadequação do quadro de funcionários, tornando-se um problema na gestão de Enfermagem.

Para que o trabalho em equipe ocorra espontaneamente, alguns fatores, quando presentes, facilitam, tais como: ajuda mútua na assistência ao paciente, independente do dimensionamento; bom vínculo entre os membros da equipe; reconhecimento pelo trabalho; colaboração; confiança; comunicação efetiva; e respeito mútuo ${ }^{(5)}$.

A liderança, segundo os participantes deste estudo, influenciava diretamente no direcionamento da equipe, o que vai ao encontro de outro estudo que relata a necessidade de uma liderança saudável para promover um ambiente de trabalho promissor e produtivo ${ }^{(15)}$.

A estimulação do trabalho em equipe é uma ferramenta importante da gestão de recursos humanos, para o alcance da excelência do cuidado ${ }^{(16)}$. Em concordância com esta afirmação, os achados deste estudo mostraram que a colaboração entre colegas de trabalho facilita a assistência, ao mesmo tempo que traz benefícios para o paciente.

Embora a maioria dos participantes desta pesquisa concordasse com a necessidade e os benefícios do trabalho em equipe, alguns afirmaram que a maioria dos profissionais de enfermagem do seu setor não conseguia fazer bem o "trabalho em equipe". A dificuldade de se trabalhar em equipe pode ser influenciada por vários fatores, a exemplo da falta de harmonia e de produtividade da equipe, diferenças culturais, diferenças de ideias e de personalidade e conflitos nos relacionamentos entre as pessoas ${ }^{(12)}$.

A não concordância encontrada entre os colaboradores deste estudo, sobre o enfermeiro ser o principal responsável pelo trabalho em equipe, pode apontar para uma equipe onde há falhas de liderança, o que pode desmotivar o trabalho em equipe. Estudos realizados com a equipe de enfermagem destaca que a maioria dos técnicos de enfermagem tem a visão da importância do enfermeiro como o líder da equipe, ressaltando seu papel na forma de incentivar as atividades coletivas em busca de resultados estipulados e na participação do crescimento profissional de $\operatorname{todos}^{(17-19)}$.

Estudo realizado em uma unidade hospitalar destacou o enfermeiro gerente como um líder criterioso, que promove o trabalho em equipe, um ambiente seguro, valoriza seus liderados e estimula os colaboradores a participar das tomadas de decisões ${ }^{(10)}$. Desta forma, destaca-se a importância do trabalho em equipe como meio de uniformizar o cuidado, alinhar percepções entre os colaboradores da equipe de enfermagem e da equipe interdisciplinar, em busca de melhores práticas somadas aos melhores resultados assistenciais. Nesse processo, a liderança do enfermeiro destaca-se como exemplo de habilidade de controle, crescimento e capacitação dos membros de sua equipe.

Importante ressaltar que a forma como os membros da equipe de enfermagem entende o trabalho em equipe e sua importância pode impactar diretamente na qualidade do cuidado. Assim, ressalta-se a importância da mudança de paradigma do ser enfermeiro líder, gestor e estar vinculado ao cuidado diretamente, em busca de melhorias coletivas e não mais individualizadas.

Destaca-se como limitação do estudo a coleta de dados ter ocorrido com uma amostra num único serviço de saúde. Sugere-se a continuidade do estudo em outros serviços com um perfil de atendimento diferente do apresentado por esta amostra, o que permitirá identificar as percepções da equipe e promover intervenções para melhorar os resultados do trabalho em equipe.

\section{Conclusão}

A opinião dos colaboradores de enfermagem que participaram deste estudo convergiu para a importância do trabalho em equipe, ao reconhecerem fatores que podiam favorecer esse trabalho, como o bom relacionamento interpessoal, colaboração e respeito entre os pares, associado ao entendimento dos objetivos e da missão institucional. Entretanto, embora não fosse uniforme a concordância sobre os benefícios propiciados pelo trabalho em equipe, entendiam que 
assegurava melhores resultados em relação ao atendimento, otimização do tempo e maior satisfação para equipe e paciente. Destacou-se ainda o papel do enfermeiro líder como essencial no desenvolvimento e na facilitação do trabalho em equipe, em busca de melhores desempenhos e atitudes.

A percepção da equipe de enfermagem em relação ao trabalho em equipe é resultado do modo como o enfermeiro conduz sua equipe. A reflexão das necessidades do grupo é indispensável para um processo de melhoria coletiva.

\section{Fonte de Financiamento:}

Coordenação de Aperfeiçoamento de Pessoal de Nível Superior (CAPES).

\section{Colaborações:}

1 - concepção, projeto, análise e interpretação dos dados: Lusinete Ventura Valentim e Reginaldo Adalberto de Luz;

2 - redação do artigo e revisão crítica relevante do conteúdo intelectual: Reginaldo Adalberto de Luz, Luciana Soares Costa Santos e Cell Regina da Silva Noca;

3 - aprovação final da versão a ser publicada: Reginaldo Adalberto de Luz, Luciana Soares Costa Santos e Cell Regina da Silva Noca.

\section{Referências}

1. Wegner RS, Godoy LP, Godoy TP, Bueno WP, Pereira MS. Trabalho em equipe sob a ótica da percepção dos gestores e funcionários de uma empresa de serviços. Pretexto. 2018;19(1):11-24. DOI: http://dx.doi.org/10.21714/pretexto.v19i1.3089

2. Peduzzi M. Trabalho em equipe e processo grupal. In: Kurcgant P, Ciampone MHT, Tronchin DMR, Fugulin FMT, Peres HHC, Massarollo MCKB, et al. Gerenciamento em enfermagem. 2a ed. Rio de Janeiro: Guanabara Koogan; 2010. p. 105-13.

3. Carmagnani MIS. Trabalho em equipe. In: Ducci AJ, Erdmann AL, Barros ALBL, Queijo AF, Brêtas ACP, Pereira AL, et al. Gestão em enfermagem: ferramenta prática segura. São Caetano do Sul: Yendis; 2011. p. 9-14.
4. Balsanelli AP, David DR, Ferrari TG. Liderança do enfermeiro e sua relação com o ambiente de trabalho hospitalar. Acta paul enferm. 2018 Mar;31(2):187-93. DOI: https://doi.org/ 10.1590/1982-0194201800027

5. Broca PV, Ferreira MA. Nursing team communication in a medical ward. Rev Bras Enferm. 2018;71(3):951-8. DOI: http://dx.doi. org/10.1590/0034-7167-2017-0208

6. Chiavenato I. O trabalho em equipe. In: Chiavenato I. Administração: teoria, processo e prática. 4a ed. Rio de Janeiro: Elsevier; 2007. p. 327-30.

7. Souza GC, Peduzzi M, Silva JAM, Carvalho BG. Trabalho em equipe de enfermagem: circunscrito à profissão ou colaboração interprofissional. Rev Esc Enferm USP. 2016;50(4):642-9. DOI: http:// dx.doi.org/10.1590/S0080-623420160000500015

8. Kessler AI, Krug SBF. Do prazer ao sofrimento no trabalho da Enfermagem: o discurso dos trabalhadores. Rev Gaúcha Enferm. 2012;33(1):49-55. DOI: https://doi.org/10.1590/ S1983-14472012000100007

9. Doriguello BM, Cláudia P. Problematização do trabalho em equipe em enfermagem: relato de experiência. Rev Bras Enferm. 2013;66:134-7. DOI: http://dx.doi.org/10.1590/ S0034-71672013000100021

10. Cardoso AS, Dall'Agnol CM. Processo grupal: reflexões de uma equipe de enfermagem. Rev Esc Enferm USP. 2011;45(6):1412-8. DOI: http://dx.doi. org/10.1590/S0080-62342011000600019

11. Landon LB, Slack KJ, Barrett JD. Teamwork and collaboration in long-duration space missions: Going to extremes. Am Psychol. 2018;73(4):563-75. DOI: https://doi.org/10.1037/amp0000260

12. Peruzzo HE, Bega AG, Lopes APA, Torquato, Haddad MCFL, Peres AM, et al. Os desafios de se trabalhar em equipe na estratégia saúde da família. Esc Anna Nery. 2018;22(4):e20170372. DOI: 10.1590/2177-9465-EAN-2017-0372

13. Rodrigues EOL, Oliveira JKA, Lopes Neto D, Campos MPA. Avaliação da liderança dos enfermeiros por auxiliares e técnicos de enfermagem segundo o método 360. Rev Gaúcha Enferm. 2015;36(4):29-36. DOI: https://doi. org/10.1590/1983-1447.2015.04.50491

14. Machado MH, Wilson Filho A, Lacerda WF, Oliveira E, Lemos W, Wermelinger $M$, et al. Características gerais da enfermagem: o perfil 
sócio demográfico. Enferm Foco. 2016;7:9-14. DOI: https://doi.org/10.21675/2357-707X.2016.v7. nESP.686

15. Araújo MPS, Medeiros SM, Quental LLC. Relacionamento interpessoal da equipe de enfermagem: fragilidades e fortalezas. Rev enferm UERJ. 2016;24(5):e7657. DOI: https://doi. org/10.12957/reuerj.2016.7657

16. Miorin JD, Camponogara S, Pinno C, Beck CLC, Costa V, Freitas EO. Prazer e sofrimento de trabalhadores de enfermagem de um pronto socorro. Texto contexto enferm. 2018;27(2):e2350015. DOI: https://doi.org/10.1590/0104-070720180002350015

17. Gvozd R, Pissinati PSC, Haddad MCFL, Montezeli JH. Uso de dinâmica de grupo como estratégia de abordagem do tema liderança saudável. Rev Enferm Centro-Oeste Min. 2017;7:e1262. DOI: https://doi.org/10.19175/ recom.v7i0.1262

18. Siman AG, Cunha SGS, Martins ES, Brito MJM. Estratégia do trabalho gerencial para alcance da acreditação hospitalar. Reme Rev Min Enferm, 2015;19(4):823-9. DOI: http://www. dx.doi.org/10.5935/1415-2762.20150063

19. Hayashida K. Liderança em enfermagem e o processo coaching no contexto hospitalar [dissertação]. Ribeirão Preto: Escola de Enfermagem, Universidade de São Paulo; 2017.

Recebido: 25 de junho 2020

Aprovado: 14 de agosto 2020

Publicado: 7 de outubro de 2020

A Revista Baiana de Enfermagem utiliza a Licença Creative Commons - Atribuição-NãoComercial 4.0 Internacional.

https://creativecommons.org/licenses/by-nc/4.0/

Este artigo é de acesso aberto distribuído sob os termos da Licença Creative Commons (CC BY-NC).

Esta licença permite que outros remixem, adaptem e criem a partir do seu trabalho para fins não comerciais. Embora os novos trabalhos tenham de lhe atribuir o devido crédito e não possam ser usados para fins comerciais, os usuários não têm de licenciar esses trabalhos derivados sob os mesmos termos. 